Além disso, o meio de proteção jurídico-constitucional, dado pela Lei Fundamental pelo recurso constitucional, serve para a atualização e realização dos direitos fundamentais, que encontram na Lei Fundamental tanto a sua sede material como o ponto de partida dos órgãos aplicadores do direito, cuja esfera de abstração encontra seus limites extremos na unidade da ordem jurídica, simultaneamente, também contextualizada e condicionada cultural e socialmente, o que possibilita primeiro a essa unidade ganhar realidade por construção, manutenção e defesa por meio de averiguação e circunscrição racional, que interessa à Constituição.

A expressão disso encontra-se, por exemplo, no desenvolvimento realizado pela jurisprudência do preceito da proporcionalidade. A sua relação com o princípio do Estado de Direito foi estabelecida por dedução, ou seja, argumentativamente; assim também foi trabalhada, cada vez, a sua relação com determinados fatos dados, ordenados diversamente pela ordem jurídica.

\title{
Los Procesos a Distancia y Otros Modos de Cooperacion Judicial Internacional en el Mercosur( ${ }^{(*)}$
}

\author{
Maxia Banca ONoodt OTaquela
}

Profesora de Derecho Internacional Privado de la Universidad de Buenos Aires y de la Universidad de Morón. Profesora de cursos de Posgrado de Derecho del Comercio Internacional de la Universidad de Buenos Aires.

\section{La Cooperacion Judicial Internacional en el Mercosur}

b

esde sus comienzos el Mercosur se ha ocupado de regular la cooperación judicial internacional, regulación que se encuentra fundamental, pero no exclusivamente, contenida en el Protocolo de Las Leñas de Cooperación y Asistencia Jurisdiccional en Materia Civil, Comercial, Laboral y Administrativa, suscripto en Las Leñas, el 27 de junio de 1992, y en el Protocolo de Medidas Cautelares, firmado en Ouro Preto el 17 de diciembre de $1994^{1}$, aprobados por Argentina por leyes 24.578 y 24.579 respectivamente y ratificados ambos por Argentina, Brasil y Paraguay.

Nos proponemos analizar en esta exposición algunos aspectos particulares de la cooperación internacional, ya que existen normas del Mercosur que prevén modos particulares de cooperación internacional, como el proceso a distancia previsto en el Protocolo de Santa María sobre Jurisdicción Internacional en Materia de Relaciones de Consumo, firmado en Fortaleza el 17 de diciembre de 1996, C.M.C. dec. 10/96.

El proceso a distancia aparece también en el Protocolo de Medidas Cautelares de 1994, que contempla otros modos de cooperación internacional.
- Publicado en El Derecho Procesal en el Mercosur. Libro de Ponencias. Santa Fe, Octubre de 1997,Santa Fe, Universidad Nacional del Litoral, 1997, págs. 327-337.

1. TELLECHEA BERGMAN, Eduardo Un instrumento para la integración juridica regional. El Protocolo de Cooperación y Asistencia Jurisdiccional en materia Civil, Comercial, Laboral y Administrativa entre los Estados Partes del Mercosur, aprobado en Las Leñas, República Argentina, el 27 de junio de 1992, en VAZQUEZ, Maria Cristina "Estudios Multidisciplinarios sobre el Mercosur", Montevideo, Fundación de Cultura Universitaria, 1995, págs. 135/163; TELLECHEA BERGMAN, Eduardo Panorama de los Montevideo, Fundación de Cultura Universitaria, 1995, págs. 135/163; TELLCHEA BERGMAN, Eduardo Panorama de los
Protocolos del Mercosur sobre Derecho Intemacional Privado, con especial referencia a aquellos relativos a la cooperación Protocolos del Mercosur sobre Derecho Intemacional Privado, con especial referencia a aquellos relativos a la cooperación
jurdica intemacional, en "Del Mercosur. Aduana. Jurisdicción. Informática. Relaciones Intercomunitarias.", Buenos Aires, Ed. juridica internacional, en "Del Mercosur. Ac 
Nos referiremos también a algunos obstáculos para la cooperación internacional derivados de normas o situaciones internas.

Por último abordaremos la aplicación de otras convenciones de cooperación internacional en la región y la compatibilización de los instrumentos del Mercosur con otros tratados internacionales.

\section{El Protocolo de Santa Maria sobre Jurisdiccion Internacional en Materia de} Relaciones de Consumo.

1. Las reglas de jurisdicción internacional en el Protocolo de Santa María.

La regla básica o general de jurisdicción internacional, como la denomina el art. 4, es el domicilio del consumidor, ya sea este actor, como sucederá habitualmente, o demandado.

Se contemplan además jurisdicciones concurrentes en beneficio exclusivo del consumidor: el lugar de celebración del contrato, el lugar de cumplimiento de la prestación de servicio o entrega de los bienes (prestación característica) y el domicilio del demandado (art. 5)

Estas jurisdicciones alternativas se abren por voluntad exclusiva del consumi- dor, manifestada expresamente en el momento de entablar la demanda (art. 5).

La regla básica establecida y el carácter excepcional de las jurisdicciones concurrentes, traen como consecuencia que raramente el proveedor litigará ante los jueces de su domicilio, ya que se privilegia la parte débil en la relación contractual, esto es, el consumidor, en cuyo beneficio el Protocolo se aparta del criterio general atributivo de jurisdicción internacional, del juez del domicilio del demandado.

La contrapartida de este beneficio del consumidor, es permitir al proveedor, normalmente demandado, realizar actos procesales a distancia.

\section{El proceso a distancia en el \\ Protocolo de Santa María}

El Protocolo de Santa María contempla la posibilidad de que el demandado realice los actos procesales más importantes del juicio, como contestar deman$\mathrm{da}$, ofrecer pruebas, e interponer recursos, ante los jueces de su domicilio (art. 9. 1.) En realidad están incluidos todos los actos procesales, ya que la norma alude a la realización de "actos procesales que de ellos deriven", es decir que además de los actos más importantes mencionados expresamente se incluye cualquier otro acto procesal. La presentación a distancia está condicionada a que esté autorizada por los principios esenciales y básicos del

2. El art. 5 dispone: También tendrá jurisdicción intemacional "excepcionalmente" y por voluntad exclusiva del consumidor, manifestada expresamente en el momento de entablar la demanda... ¿Qué significa excepcionalmente? Creo que no agrega nada a frase siguiente: que operan por voluntad exclusiva del consumidor. Cabe preguntarse si el consumidor no manifestó expresamante al iniciar la demanda que optaba por esa juriscicción jel juez debería requerirle que haga una declaración en ese sentido 0 debería declararse incompetente de oficio? La primera alternativa parece más apropiada.

Revista da Faculdade de Direito da UFRGS, v. 15, 1998

ordenamiento procesal del tribunal actuante (art. 9.1.)

El juez del domicilio del demandado, quien actúa como juez requerido, remite la documentación al juez requirente a través de Autoridad Central, según el procedimiento establecido por el Protocolo de Las Leñas (art. 9.1 y 9.3)

Para que sea posible la realización de actos procesales a distancia, se proveen comunicaciones entre los jueces intervinientes. El juez requirente - ante quien tramita el proceso -, tiene que informar al juez requerido - juez del domicilio del demandado - :

a) el derecho aplicable a la relación de consumo (art. 9.4): El juez donde tramita el proceso tendrá que determinar el derecho aplicable al fondo del asunto, al dar traslado de demanda y ordenar el exhorto para notificar dicho traslado, a diferencia de lo que sucede normalmente, que el juez declara en la sentencia el derecho aplicable al caso.

b) el derecho procesal del Estado donde tramita el proceso, certificada por el juez requirente, a fin de que el proveedor demandado pueda realizar los actos procesales a distancia (art. 9.4). Esta información deberá necesariamente estar contenida en el exhorto que se libre para notificar el traslado de deman da, ya que si bien el demandado puede realizar los actos procesales ante el juez de su domicilio, debe hacerlo de acuerdo a la ley procesal del país donde tramita el juicio (art. 10).

¿Cómo se solucionarán problemas como la exigencia de firma de letrado matriculado en la jurisdicción donde tramita el juicio? Dado que las normas procesales aplicables son las del lugar del juicio (art. 10), si ellas exigen la intervención de abogado, habría que exigirlo. Pero, si es necesario que intervenga un abogado del país donde tramita el juicio, ique utilidad tiene la presentación ante el juez del domicilio del demandado?

Dado que se desvirtuaría la finalidad del proceso a distancia, que es evitar que el demandado tenga que litigar en otro país distinto del de su domicilio, hay que interpretar que no se requerirá la firma de abogado matriculado en el país donde tramita el juicio, quedando suplido el recaudo con la firma de abogado del país del domicilio del demandado.

\section{El Proceso a Distancia y Otros Modos de Cooperacion en el Protocolo de Medidas Cautelares.}

La traba de medidas cautelares en el extranjero torna mucho más difícil la cooperación judicial, por la incidencia del derecho de fondo - que aún no ha sido declarado en forma definitiva - en la adopción de estas medidas, y por la circunstancia de que implican ejercer coerción sobre los bienes o las personas.

Si en las diligencias de mero tramite y en las medidas de prueba, el papel del juez requerido es relativamente reducido - ya que prestará el auxilio judicial salvo que medien razones de orden público internacional - y en el reconocimiento de senten- 
cias extranjeras, sus facultades crecen notablemente ${ }^{3}$, cuando se trata del cumplimiento de medidas cautelares en el extranjero, se reparten en forma más o menos equilibrada los ámbitos de aplicación de las leyes del lugar donde tramita el proceso y del lugar de cumplimiento de la medida y la competencia de uno y otro juez, para resolver determinados aspectos del proceso cautelar.

De acuerdo al Protocolo de Medidas Cautelares de $1994^{4}$, el juez requirente, es decir el juez del Estado donde tramita o deberá tramitar el proceso principal, es quien resuelve sobre la admisibilidad de la medida cautelar, aplicando su ley (art. 5).

Este juez del proceso principal es quien resuelve la oposición que el demandado o terceros pudieran formular a la medida cautelar trabada y lo hace aplicando su ley (art. 9, segundo párrafo), salvo que la oposición sea relativa al dominio u otros derechos reales, en cuyo caso la cues-

. Especialmente, en el análisis de la jurisdicción indirecta que según el sistema originario del Protocolo de Las Leñas (art. 20 inc. c) debe ser juzgada de acuerdo a la ley del Estado requerido. Los Protocolos posteriores del Mercosur que regulan la jurisdicción internacional han ido modificando parcialmente esta norma, al disponer que las normas de jurisdicción directa acordadas entre los países del Mercosur, regulen también la jurisdicción indirecta: Protocolo de Buenos Aires sobre Jurisdicción Intemacional en Materia Contractual, Buenos Aires, 5 de agosto de 1994. C.M.C. dec. 1/94 (art. 14); Protocolo De Santa María sobre Jurisdicción Intermacional en Materia de relaciones de consumo. Santa María, 17 de diciembre de 1996. C.M.C. dec. 10/96 (art. 12) . Sin embargo, ni el Anexo ll al Acuerdo sobre Transporte Multimodal, ni el Protocolo De San Luis en materia de responsabilidad civil emergente de accidentes de tránsito entre los Estados Partes del Mercosur. Potrero de los Funes, provincia de San Luis, 25 de junio de 1996. C.M.C. dec. 1/96, hacen referencia a la jurisdicción indirecta, a pesar de contener normas sobre jurisdicción. A pesar de la omisión, la solución será indudablemente la misma: el análisis de la jurisdiccín indirecta deberá realizarse de acuerdo a las normas convencionales del Mercosur y no según las normas de jurisdicción de fuente interna de los respectivos países.

4. Sobre el Protocolo de Medidas Cautelares puede verse DREYZIN de KLOR, Adriana S. Algunas reflexiones sobre el Protocolo de Medidas Cautelares, en Revista de Derecho Privado y Comunitario, $n^{2} 8$ "Nulidades", Santa Fe, Rubinzal-Culzoni, 1995, págs.
513-539. Noodt Taquela, María Blanca Asimetrias conceptuales y normativas en el Mercosur i Se puede trabar hoy un embargo 513-539. Noodt Taquela, Maria Blanca Asimetrias conceptuales y normativas en el Mercosur ¿Se puede trabar hoy un embargo preventivo en Brasi? en Revista del Derecho del Mercosur, Buenos Aires, suplemento, junio de 1998, donde se comenta la

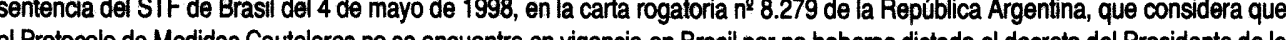
el Protocolo de Medidas Cautelares no se encuentra en vigencia en Brasil por no haberse dictado el decreto del Presidente de la
Repulica.

Revista da Faculdade de Direito da UFRGS, v. 15, 1998
1979, CIDIP-II 5 aprobada por Argentina por ley 22.921 y en el Tratado de Derecho Procesal Internacional de Montevideo de 1940 (arts. 13 y 14), aunque el Protocolo del Mercosur ha desarrollado más esta forma de cooperación internacional.

La resolución de la oposición la efectúa el juez requirente según sus leyes, salvo que la medida sea absolutamente improcedente, en cuyo caso el mismo juez requerido dispone el levantamiento según sus leyes, como también podría haber rechazado directamente la medida, sin dar cumplimiento al requerimiento de cooperación (art. 8).

La ley del Estado del juez requirente se aplica también para determinar el plazo que existe para iniciar el proceso principal, bajo pena de ineficacia de la medida cautelar preparatoria (arts. 13 y 14 inc. a) El juez requirente debe comunicar ese plazo al solicitar la medida y posteriormente comunicar la promoción de la demanda principal (art. 14), así como el juez requerido debe comunicar la fecha de traba de la me dida o las razones por las cuales no fue cumplida (art. 15)

En suma, las cuestiones que deben ser resueltas por el Juez requerido, según sus leyes, son varias:

a) El cumplimiento de las medidas cautelares, en tanto los bienes estén situados o las personas residan en ese país.

b) La determinación y efectivi zación de la contracautela. (art. 6 )
6)

c) La ejecución de la medida (art.

d) La modificación de las medidas cautelares, incluyendo la reducción y sustitución de las mismas (art. 7 inc. a).

e) Las sanciones por malicia y abuso (art. 7 inc. b).

f) Las oposiciones basadas en el dominio y demás derechos reales (art. 7 inc. c), como las tercerías de dominio, privilegios de acreedores hipotecarios y prendarios.

g) El rechazo o levantamiento de la medida por su absoluta improcedencia (art. 8).

h) La concesión de un efecto limitado territorialmente, cuando se trata de medidas cautelares respecto de me nores, hasta tanto exista sentencia firme (art. 12).

Como puede advertirse el Protocolo de Medidas Cautelares, distribuye de un modo más o menos equilibrado las cuestio nes en las que compete entender al juez de Estado donde tramita el proceso principa y al juez del Estado donde deben cumplirse las medidas cautelares.

El Protocolo de Medidas Cautelares de Mercosur no contempla las medidas cautelares territoriales, es decir aquellas que pueden ser solicitadas y adoptadas di rectamente por el juez del lugar donde se encuentran los bienes o residen las perso nas, aunque no sea el juez investido de ju

5. La Convención Interamericana sobre Cumplimiento de Medidas Cautelares se encuentra vigente en siete Estados: Argentina Colombia, Ecuador, Guatemala, Paraguay, Perú y Uruguay. Dado que los únicos paises ratificantes del Tratado de Derecho Procesal Intemacional de Montevideo de 1940, son parte en la Convención Interamericana, las normas del Tratado de 1940 referidas a medidas cautelares han dejado de tener vigencia. 
risdicción internacional para intervenir en el proceso. En cambio, este tipo de medidas están contempladas en la Convención Interamericana sobre Cumplimiento de Medidas Cautelares (art. 10) y en la Convención de Bruselas de 1968 (art. 24).

La medida adoptada por el juez del lugar de situación de los bienes queda sujeta a la confirmación del juez con jurisdicción internacional para entender en el proceso principal. Aparece así otro modo de cooperación ente los jueces de Estados diferentes.

\section{Obstaculos Para la \\ Cooperacion Judicial \\ Internacionaal Derivados \\ de Normas o Situaciones Internas}

La aprobación de normas convencionales para facilitar la cooperación judicial internacional es necesaria pero no suficiente para que esta se concrete efectivamente, ya que las normas o determinadas situacio nes internas de los Estados, pueden obstaculizar la cooperación.

Uno de los obstáculos más notorios está dado por la Constitución de Brasil de
1988, que en su art. 102 inc. $1^{\circ}$, apart. h), dispone que compete al Supremo Tribunal Federal la homologación de las sentencias extranjeras y la concesión de exequatur a las cartas rogatorias ${ }^{6}$, el que puede ser atribuido por su reglamento interno al presidente del Tribunal.

La circunstancia de que los exhortos tengan que pasar necesariamente por el Supremo Tribunal Federal, dificulta la cooperación judicial internacional.?

El art. 17 de la ley de introducción al Código Civil de Brasil, que niega eficacia a los actos provenientes de otro país, cuando afectaran la soberanía nacional, el orden público y las buenas costumbres, ha sido utilizado como base legal para negar, a veces, la cooperación internacional requerida. ${ }^{8}$

El análisis de la jurisdicción indirecta en el cumplimiento de los exhortos internacionales ha constituido uno de los obstáculos para la cooperación. El Supremo Tribunal Federal ha concedido el exequatur a las cartas rogatorias cuando exista jurisdicción concurrente, en los términos del art. 88 del Código del Proceso Civil pero aclarando que cabrá al interesa-

6. El sistema se remonta al siglo XIX, como lo explican ARAUJO Nadia de, SALLES, Carlos Alberto de y ALMEIDA, Ricardo $R$. Cooperaçao interiurisdicional no MERCOSUL, en BASSO, Maristela "MERCOSUL. Seus efeitos jurídicos, econômicos e pólicos nos Estados lica que que el exequatur debia ser conferido por el Gobierno Federal, exigiendolo para las cartas rogatorias (art. 12.4). La Constitución de 1937 establecio que ex. en la Constitución de 1988. La reglamentación del trámite de las Cartas Rogatorias ha sido efectuada por la Portaria $n^{2} 26$ del Ministerio de Relaciones Exteriores, del 14 de agosto de 1990, publicada en D.O.U. del 15/8/90.

7. En 1995 se juzgaron el Supremo Tribunal Federal 35. 214 procesos, lo que implica 3.200 procesos por cada uno de los 11 ministros que lo integran. Revista VEJA, ne 1474 del 11 de diciembre de 1996, págs. 58-66, citada por UBALDO, Edson Nelson O Protocolo de Las Leñas, ponencia presentada en el VI Encuentro Internacional de Derecho de América del Sur. Santiago de Chile, 22 al 24 de mayo de 1997.

8. ARAUJO, Nadia de y otros, ob. cit., pág. 350; DOLINGER, Jacobo Direito Intermacional Privado (Parte Geral) 3a. ed., Río de Janeiro, Renovar, 1994, pág. 346 do aceptar o no la jurisdicción extranjera. A partir de 1992, el Supremo Tribunal Fe. deral ha declarado que era jurisprudencia firme del Tribunal, que la facultad del demandado de no aceptar la jurisdicción extranjera, no obsta a la concesión del exequatur para el cumplimiento de la carta rogatoria. ${ }^{9}$

Los autores brasileños han encontrado que esta jurisprudencia resulta concordante con lo dispuesto por el art. 9 de la Convención Interamericana sobre Exhortos o Cartas Rogatorias, firmada en Panamá, el 30 de enero de 1975, CIDIP-I ${ }^{10}$, aprobada por Argentina por ley 23.503, que dispone: $E l$ cumplimiento de exhortos o cartas rogatorias no implicará en definitiva el reconocimiento de la competencia del órgano jurisdiccional requirente ni el compromiso de reconocer la validez o de proceder a la ejecución de la sentencia que dictare.

En realidad, la interpretación que se ha dado a la norma mencionada es que elimina el análisis de la jurisdicción indirecta en el cumplimiento de los exhortos, aunque no se prohiba en forma expresa. ${ }^{11}$. La jurisprudencia de Brasil en tanto se refiere sólo a los casos de jurisdicción concurrente, deja abierta la posibilidad que se deniegue el cumplimiento de un exhorto, por existir jurisdicción exclusiva de los tribunales de Brasil.

9. ARAUJO, Nadia de y otros, ob. cit., pág. 350 y jurisprudencia citada en notas 38 y 39 .

10. La Convención Interamericana sobre Exhortos o Cartas Rogatorias se encuentra vigente en 17 Estados: Argentina, Brasil, Colombia, Costa Rica, Chile, Ecuador, El Salvador, España, Estados Unidos de América, Guatemala, Honduras, México, Panamá, Paraguay, Perú, Uruguay y Venezuela.

11. La Convención de La Haya sobre Obtención de Pruebas en el extranjero de 1970 prohibe en forma expresa el análisis de la jurisdicción indirecta (art. 12).

12. HUCK, Hermes M. e SILVA FILHO, Antonio C. da A citaçăo por carta rogatória, en BAPTISTA, L.O. (org.) "Direito e Comercio Internacional: Tendencias e Perspectivas- Estudos em homenagem ao Prof. Irineu Strenger,", Sao Paulo, LTr., 1994, cit. por ARAUJO, Nadia de y otros, ob. cit., pág. 351 , nota 42.
La falta de notificación al deman dado por carta rogatoria, ha sido uno de los motivos más frecuentes para rechazar e reconocimiento de una sentencia extran era en Brasil, como también en Argentina, por ejemplo si se utilizó la vía postal.

Es interesante señalar que la refor ma de la ley 8710 del 24 de septiembre de 1993 del Código del Proceso Civil de Brasil, (art. 222), pero como la nor quier comarca del país, la doctrina ha interpretado que no resulta aplicable a las ros, ya que estaría comprometida la soberanía nacional. ${ }^{12}$

La diversidad de legislación proceen cada provincia argentina, de raí constitucional (art 75 inc. 12 de la Constivista como una dificultad en materia de cooperación judicial internacional por los autores brasileños. Si bien la supremacía de recepción constitucional (art. 75 inc. 22) as diferentes reglamentaciones procesales incluso por vías de acordadas de los tribu nales, pueden obstaculizar la cooperación udicial internacional.

En Argentina, la Ley de mediación

Revista da Faculdade de Direito da UFRGS, v. 15, 1998 os tratados internacionales tiene expres 

principal, como sucede en el derecho ar- dificultades, por ejemplo en relación a las medidas cautelares, dado que la ley impide la promoción de la demanda, hasta tanto se haya pasado por la instancia previa, no judicial, de la mediación obligatoria. La determinación del plazo para iniciar el proceso principal, una vez trabada la medida cautelar preparatoria, puede presentar dificultades, ya que existe una imposibilidad legal de promover la demanda y la media ción no tiene carácter de demanda judicial.

La mediación obligatoria también puede constituir una dificultad para disponer algunas medidas cautelares que requieren la iniciación conjunta del proceso gentino con la intervención societaria, que exige la promoción de la acción de remoción del directorio (arts. 113 y 114 de la ley de sociedades 19.550, modificada por la ley 22.903), o la anotación preventiva de litis (art. 229 del Código Procesal Civil y Comercial de la Nación). ${ }^{13}$

Dado que la ley argentina 24.573 no ha contemplado estas situaciones, debería razonablemente entenderse que la iniciación del procedimiento de mediación cumple el requisito de iniciación de la demanda a los efectos de las medidas cautelares.

La cooperación judicial internacional puede resultar obstaculizada no sólo por normas internas, sino también por la inexistencia o falta de implementación de mecanismos para hacerla efectiva. Por

ejemplo, las dificultades que tienen los tribunales para realizar de oficio las diligencias necesarias para prestar la cooperación internacional.

Se ha sostenido doctrinariamente en Brasil que el trámite de oficio previsto en el art. 8 del Protocolo de Las Leñas para el cumplimiento de los exhortos, se extiende al reconocimiento y ejecución de sentencias extranjeras, que de acuerdo al art. 19 del mismo Protocolo, tramita ahora por vía de exhorto y por intermedio de la Autoridad Central. ${ }^{14}$

Más allá de las posturas doctrinarias y discusiones teóricas, puede advertirse que el trámite de oficio se torna una imposibilidad material en los sistemas judiciales existentes en los países del Mercosur, particularmente en los casos en que se pretende la ejecución de la sentencia. Será necesaria la designación de un abogado en el país de ejecución para que embargue bienes, inste el remate de los mismos y desde ya, para que conteste la defensas que el demandado pueda plantear al pedido de reconocimiento de la sentencia. El trámite de oficio quizás pueda cumplirse cuando se trata del mero reconocimiento de la sentencia, y no de la ejecución de la misma, por ejemplo, para anotarla en registros públicos, en cuestiones de estado civil, como sentencias de divorcio o de adopción.

De cualquier modo, será necesario que los Estados Parte del Mercosur contem13. Fácil es advertir que no se trata solamente de un obstáculo para la cooperación internacional, sino de un problema que se presenta también en los casos internos.

14. Se ha discutido en Brasil si puede haber "acción" sin iniciativa de su titular. Ver: ARAUJO, Nadia de y otros, ob. cit., pág. 358. Pienso que se trata de una objeción exclusivamente teórica, que en todo caso quedaría suplida con la petición que el interesado formulase ante el juez que dictó la sentencia a fin de que se libre el exhorto para obtener el reconocimiento. plen la manera de hacer efectiva la cooperación judicial, a través de mecanismos apropiados, ya sea para el reconocimiento de sentencias, el cumplimiento de los exhortos, como para la realización de los actos procesales a distancia.

\section{Aplicación de Otras \\ Convenciones de Cooperacion Judicial Internacional en el Mercosur}

La existencia de una normativa propia del Mercosur en materia de cooperación judicial internacional, no impide la aplicación de otros tratados internacionaya sean bilaterales o multilaterales, especialmente las convenciones de CIDIP.

Las normas de relación con otras convenciones del Protocolo de Las Leñas (art. 35), y del Protocolo de Medidas Cautelares (art. 26), permiten la aplicación de disposiciones de otras convenciones más favorables a la cooperación. ${ }^{15}$.

En realidad, cabe también la aplicaaspectos no regulados por los Protocolos les vigentes entre los Estados interesados, ción de normas de otras convenciones en del Mercosur, en virtud de los principio generales en materia de aplicación de tra tados internacionales, en particular el art. 59 de la Convención de Viena sobre el Dere cho de los Tratados de $1969^{16}$, aprobada por Argentina por ley 19.865 y ratificada por los cuatro países del Mercosur.

Por ejemplo, en materia de vías de transmisión de los exhortos, el Protocolo de Las Leñas solo contempla la remisión través de Autoridad Central ${ }^{17}$, en tanto las Convenciones Interamericanas, permiten que la transmisión se efectúe por las parte interesadas, en cuyo caso se requiere lega lización, por vía diplomática o consular y por vía judicial directa cuando se trata de zonas fronterizas, en estos casos sin necesidad de legalizaciones (arts. 4, 6 y 7 de la Convención Interamericana sobre Exhortos Cartas Rogatorias, arts. 11 y 13 de la Con vención Interamericana sobre Recepción de Pruebas en el Extranjero ${ }^{18}$, ambas suscriptas en Panamá del 30 de enero de 1975, CIDIP I, aprobadas por Argentina por leyes 23.503 y 23.481 respectivamente).

La mayor facilidad que supone la tra mitación por Autoridad Central, exenta de Leñas) no puede impedir que las partes uti legalizaciones (art. 26 del Protocolo de La

15. El art. 35 del Protocolo de Las Leñas dispone: El presente Protocolo no restringirá las disposiciones de las convenciones que sobre la misma materia hubieran sido suscriptas anteriormente entre los Estados Partes en tanto no lo contradigan. El art. $26 \mathrm{~d}$ Protocolo de Medidas Cautelares, en forma más clara, establece: Este Protocolo no restringirá la aplicación de disposiciones más favorables para la cooperación contenidas en otras Convenciones sobre Medidas Cautelares en vigor con carácter bilateral 0 multilateral entre los Estados Partes.

16. NOODT TAQUELA, María Blanca Arbitraje intemacional entre particulares en el Mercosur, en Revista Jurisprudencia Argentina Buenos Aires, semanario del 14 de agosto de 1996, págs. 39/45

17. En cambio, el art. 19 del Protocolo de Medidas Cautelares contempla la transmisión por vía diplomática o consular, por medio de la Autoridad Central, por las partes interesadas y por los jueces de zonas fronterizas.

18. La Convención Interamericana sobre Recepción de Pruebas en el Extranjero se encuentra vigente en 15 Estados: Argentina Colombia Costa Rica, Chile, Ecuador, El Salvador, Guatemala Honduras, México, Panamá, Paraguay Perú, República Domincana, Uruguay y Venezuela. 
licen las otras vías previstas en las Convenciones Interamericanas, que pueden resultarles a veces más convenientes, particularmente la transmisión por las propias partes interesadas.

La posibilidad de transmisión directa judicial en zonas fronterizas sin legalización, que permite el art. 7 de la Convención Interamericana sobre Exhortos o Cartas Rogatorias, resulta muy útil en el Mercosur, porque de lo contrario, en el sistema de Brasil el exhorto tiene que ser remitido a Brasilia para obtener el exequatur del Supremo Tribunal Federal, aunque se trate del trámite más simple. ${ }^{19}$

Otra diferencia entre los Protocolos del Mercosur y las Convenciones Interamericanas, se advierte en las frases utilizadas para la formulación de la cláusu. la de orden público, ya que el Protocolo de Las Leñas no menciona el adverbio "manifiestamente", cuando se refiere a que la medida solicitada atente contra los principios de orden público del Estado requerido (art. 8) y la Convención Interamericana sobre Exhortos o Cartas Rogatorias expresa "manifiestamente contrario a su orden público" (art. 17), sin mencionar los "principios". Deberá acudirse en este aspecto a la formula superior utilizada por el art. 5 de la Convención Interamericana sobre Normas Generales de Derecho Internacional Privado, suscripta en Montevideo el 8 de mayo de 1979, CIDIP-II ${ }^{20}$, aprobada por Argentina por ley 22.921, que dispone: La ley declarada aplicable por una Convención de Derecho Internacional Privado podrá no ser aplicada en el territorio del Estado Parte que la considerare manifiestamente contraria a los principios de su orden público.

\section{Conclusiones}

1) La cooperación judicial internacional en el Mercosur se encuentra regulada fundamental, pero no exclusivamente, por los Protocolos de Las Leñas de 1992 y de Medidas Cautelares de 1994, aprobados por Argentina por leyes 24.578 y 24.579 respectivamente y ratificados ambos por Argentina, Brasil y Paraguay.

2) El Protocolo de Santa María de 1996 sobre jurisdicción internacional en materia de relaciones de consumo, introduce la posibilidad de que el proveedor demandado realice actos procesales a distancia (art. 9), como contrapartida a la jurisdicción atribuida los jueces del domicilio del consumidor como regla básica. La contestación de de manda y otros actos procesales se presentan ante el juez del domicilio del demandado, quien los remite al juez donde tramita el proceso, por exhorto, a través de Autoridad Central.

3) La traba de medidas cautelares en el extranjero requiere una distribución equilibrada de la intervención de jueces y leyes del país donde tramita el proceso y del país donde debe cumplirse la medida cautelar. Así se ha encarado en el Protocolo de Medi das Cautelares de 1994, que tiene su antecedente en la Convención Interamericana sobre Cumplimiento de Medidas Cautelares, de Montevideo de 1979, CIDIP-II.

4) El Protocolo de Medidas Cautelares prevé también la realización de actos procesales a distancia, cuando media oposición del demandado o de un tercero, la que se presenta ante el juez que hizo efectiva la medida, pero es resuelta por el juez del proceso principal, salvo algunos supuestos (arts. 9, 2 párrafo, 7 inc. c y 8 ).

5) Las normas internas pueden cons tituir un obstáculo para la cooperación internacional. El caso más notorio es el art. 102, inc. $1^{\circ}$, h) de la Constitución de Brasil de 1988, que atribuye al Supremo Tribunal Federal competencia para la homologación de sentencias extranjeras y la concesión del exequatur a las cartas rogatorias. La exis tencia de legislación procesal propia de cada provincia en Argentina, constituye también una dificultad para la cooperación internacional.
6) La existencia de normas propias del Mercosur en materia de cooperación internacional no impide la aplicación de otras convenciones sobre la materia, por ejemplo las Convenciones de CIDIP, en tanto permiten utilizar otras vías de transmisión de los exhortos, además de la Autoridad Central, ya que el mismo Protocolo de Las Leñas (art. 35) contempla la aplicación de otras convenciones y con ello se facilita la cooperación.

7) Los obstáculos que hemos señalado no deben impedirnos ver que el proceso de integración del Mercosur ha contribuido favorablemente, junto con otros factores más generales, a la cooperación judicial internacional entre los países miembros. Afortunadamente, Brasil revirtió su posición contraria a ratificar tratados internacionales y comenzó a incorporarse al proceso de CIDIP. A pesar de las dificultades en la negociación de los instrumentos relativos a la cooperación internacional, actualmente el Mercosur cuenta con varios Protocolos que la facilitan notoriamente $y$ que en su mayoría ya han sido ratificados por Brasil.

19. Ver: ARAUJO, Nadia de y otros, ob. cit., pág. 346. Si bien el sistema argentino no requiere exequatur para los exhortos, la remisión a Buenos Aires de un exhorto de un juez de Foz de Iguazú que debe ser diligenciado en Puerto lguazú, Argentina,

20. La Convención Interamericana sobre Normas Generales de Derecho Intemacional Privado, se encuentra vigente en 10 Estados: Argentina, Brasil, Colombia, Ecuador, Guatemala, México, Paraguay, Perú, Uruguay y Venezuela. 